\title{
A RESPONSABILIDADE DO ESTADO PELAS CONDUTAS OMISSIVAS DE SEUS AGENTES NA ÁREA DA SAÚDE
}

\section{ARTIGO ORIGINAL}

ROCHA, Alexandra Rayara da Silva ${ }^{1}$

RODRIGUES, Eduardo Henrique Oliveira ${ }^{2}$

AMARAL, Fernando Paiva Gomes do ${ }^{3}$

ROCHA, Alexandra Rayara da Silva. RODRIGUES, Eduardo Henrique Oliveira. AMARAL, Fernando Paiva Gomes do. A responsabilidade do Estado pelas condutas omissivas de seus agentes na área da saúde. Revista Científica Multidisciplinar Núcleo do Conhecimento. Ano 05, Ed. 06, Vol. 05, pp. 48-65. Junho de 2020. ISSN: 2448-0959, Link de acesso: https://www.nucleodoconhecimento.com.br/lei/condutas-omissivas

\section{RESUMO}

Os agentes da área da saúde atribuem a responsabilidade ao Estado não apenas por suas condutas comissivas, mas também as omissivas, uma vez que a não ação onde em regra haveria o dever de agir também é punida. Esta pesquisa foi realizada com o intuito de descobrir de que maneira o agente pode ser responsabilizado pelas suas condutas omissivas na área da saúde, como também quais são as punições que este recebe. Os dados foram colhidos através de uma minuciosa pesquisa bibliográfica e jurisprudencial, a fim de apresentar informações doutrinárias, como também o que é adotado pelos tribunais brasileiros, a pesquisa ocorreu de maneira qualitativa. Constatou-se que há diversos entendimentos de como o Estado deve ser

\footnotetext{
${ }^{1}$ Graduada em Direito. Pós-graduanda em Direito Penal e Criminologia.

2 Graduando em Direito.

${ }^{3}$ Graduando em Direito.
} 
responsabilizado, mas que na prática, essa responsabilização ocorre através da existência de nexo entre a conduta omissiva e a lesão provocada, verificando-se não somente o resultado, mas qual a participação da Administração Pública neste.

Palavras-chave: Culpa, jurisprudência, omissão, responsabilidade, saúde.

\section{INTRODUÇÃO}

A administração pública é um importante instrumento para o andamento correto da máquina pública, e junto com as ações da administração pública vêm suas consequências, assim como as de suas omissões, pois em muitas situações, os agentes da administração têm a obrigação e dever de agir diante de determinadas situações, o que ocorre é que em alguns casos a atuação dos agentes não acontece, e isso na maioria das vezes traz consequências negativas para a administração, é o que ocorre na atuação dos agentes na área da saúde, uma omissão de um agente como esse pode gerar danos irreversíveis e irreparáveis, dessa maneira, é muito importante avaliar como esses agentes podem ser responsabilizados pelos atos que deixaram de praticar e que fazem parte do rol de obrigações.

O direito à saúde é um direito fundamental, disposto na Constituição Federativa da República Brasileira, que vê a saúde como fator necessário para a manutenção da vida e dignidade humana. Assim como elucidado por Humenhuk (2004), sendo a saúde um direito fundamental de todos os cidadãos, cabe ao Estado promover o acesso a ela por todas as pessoas, partindo-se então da premissa que a saúde é fator determinante para a garantia da dignidade humana. A responsabilidade dos agentes da área da saúde por omissões, é um tema muito discutido atualmente, que elenca vários fatores, como por exemplo, a responsabilidade desses agentes diante dos casos de omissão que causam danos, a responsabilidade da administração diante dessas omissões de seus agentes, que é previsto na Constituição Federal, que prevê a responsabilidade da Administração, por condutas de seus agentes que causem danos a terceiros, sendo possível a ação de regresso. 
Inicialmente, vale definir o que é responsabilidade civil do Estado, como a medida aplicada como forma de reparar os danos sofridos moralmente ou materialmente por terceiro em razão de ação ou omissão do agente que the faça as vezes. Essas obrigações se originam de várias fontes, com por exemplo, a lei, o ato ilícito, entre outros. É importante ainda frisar que existem dois tipos de responsabilidade, a objetiva e a subjetiva, a primeira decorre da responsabilidade que não necessita de ser comprovada, no caso da administração, pelo fato de esta assumir a teoria do risco, já a subjetiva se faz presente quando há uma maior comprovação da culpa. A culpa subjetiva na maioria das vezes é atribuída ao agente quando este é chamado nas ações de regresso, já que na maioria dos casos o Estado é o agente mais acessível para os terceiros ingressarem com ração na esfera judicial. A responsabilização pode decorrer tanto da ação ou da omissão dos agentes que fazem as vezes do Estado perante a sociedade através dos serviços. O Estado tem a obrigação de atuar em certas situações, e a ausência dessa atuação pode ensejar várias consequências, como por exemplo, a responsabilização do Estados por condutas omissivas de seus agentes, seja qual for o nível hierárquico, e não importando se essa omissão ocorreu dentro das competências do agente. Havendo a relação entre a omissão e o resultado lesivo a terceiro, confugira a necessidade de indenizar a pessoa lesionada, já que é dever do Estado determinada prestação de serviços.

O direito à saúde é fundamental para todos e deve ser tratado com prioridade em todas as ações que dizem respeito a esse setor. Dessa maneira, se uma pessoa necessita de um atendimento hospitalar, ou um tratamento para um problema de saúde, é dever do Estado criar maneiras para que esse serviço seja efetivado da melhor maneira possível, sendo assim, efetivando o que está elencando pela Constituição Federal é assim como é admitido em muitas jurisprudências. É fato que é dever do Estado providenciar as melhores maneiras de prestar serviços relacionados à saúde, e assim também garantir maneiras que garantam que seus agentes atuem para concretizar tal serviço, como por exemplo disponibilizar materiais necessários, e até mesmo medicamentos para tratamentos. 
"O direito a saúde é prerrogativa constitucional indisponível, garantido mediante a implementação de políticas públicas, impondo ao Estado a obrigação de criar condições objetivas que possibilitem o efetivo acesso a tal serviço." (Al 734.487-AgR, rel. Min. Ellen Gracie, julgamento em 3-8-2010, Segunda Turma, DJE de 20-8-2010.) Vide: RE 436.996-AgR, rel. Min. Celso de Mello, julgamento em 22-11-2005, Segunda Turma, DJ de 3-2-2006; RE 271.286-AgR, rel. Min. Celso de Mello, julgamento em 129-2000, Segunda Turma, DJ de 24-11-2000.

A omissão pode se dar a partir da ausência do serviço, da má prestação desse, da prestação tardia, sendo assim, a omissão decorre da inércia do Estado diante de uma situação que possa resultar na lesão de terceiro. É um culpa anônima pois não deve ser individualizada, já que é atribuída ao serviço do Estado no geral, é a ausência da prestação de serviços, esta que é ilícita, pois sempre está presente em situações em que há a presença de negligência, imperícia e imprudência. No caso da saúde, o Estado deixa de prover serviço quando o que há de mais básico começa a faltar, assim, dessa maneira o que mais ocorre na atualidade são omissões da administração pública em hospitais, postos de saúde, a ausência de remédios para tratamento de problemas comuns na saúde, pessoas que precisam de operações com urgência, muitas vezes ficam muito tempo em filas para conseguir, isso quando ela ainda suporta até o momento da cirurgia, são constantes as reclamações que a população faz em decorrência da má e da ausência de prestação de serviços em hospitais, prontos socorros, unidades de pronto atendimento, postos de saúde, o que afeta a sociedade em geral.

A administração pública é regida pelo princípio da legalidade, este que deve estar presente em todas as condutas dos agentes da administração, assim, a omissão não é nada mais que a violação desse princípio, já que deixar de agir como está regulamentado é ir contrariamente a legalidade. De acordo com Celso Antônio Bandeira de Mello, o princípio da legalidade é o pilar do Estado de Direito, já que esse não existindo não há que se falar em outros, já que é fator determinante para regulamentação do direito. 
Vale ressaltar que a partir do momento em que o Estado deixa de cumprir seus deveres até então tido como essenciais, surge a necessidade de reparar o dano ou indenizar de forma pecuniária, pois neste contexto de omissão, há uma pessoa do outro lado que que sofreu o dano e que necessita de uma segurança jurídica de reparação, sendo o Estado neste caso o responsável mais apto a sanar esta necessidade do lesado.

\section{TEORIAS DA CULPA DO AGENTE}

\subsection{EVOLUÇÃO HISTÓRICA}

A ciência do direito acompanha a evolução da sociedade, e neste caso não é diferente, a responsabilidade civil, principalmente a do estado sofreu diversas mudanças para acompanhar esta evolução, doutrinas e jurisprudências realizam este trabalho, envolvendo amplos debates afim de que se chegue na melhor alternativa.

Posto isto, historicamente tem-se, que esta responsabilidade da administração pública, nem sempre existiu, em um primeiro momento o estado não era responsabilizado pela conduta de seus agentes, característica advinda dos estados absolutistas e autoritários, a Administração Pública restava-se inalcançável, a opressão permanecia.

Contudo, como dito anteriormente a sociedade clamou por mudanças, e elas chegaram, passou-se a alcançar o Estado atribuindo a ele a responsabilidade civil subjetiva, aquela que necessita além do ato ilícito, nexo de causalidade e dano o elemento culpa do agente, desta forma, para que se tenha a reparação, faz-se necessário a comprovação de culpa, o que por diversas vezes ainda dificulta a devida reparação que merece os indivíduos, por serem hipossuficientes diante do estado, não possuem a mesma capacidade de produção de provas que o ente público.

Como marco histórico desse momento, pode-se citar o famoso caso de Agnés Blanco, que ocorreu no ano de 1871, onde foi ferida ao passar em frente a uma fábrica estatal, comandada por quatro funcionários, em decorrência deste ferimento teve sua perna 
amputada, assim seu pai ingressou com uma ação judicial em face do Estado, visando a indenização a fim de reparar o dano causado à sua filha, já que havia ocorrido um ato ilícito por parte do agentes da empresa pública, à época surgiu ainda uma dúvida quanto à competência para decidir, se seria judicial ou administrativa, ficou decidido que seria administrativa, por decisão do tribunal foi concedida à vítima uma pensão vitalícia, surgindo assim a teoria do risco administrativo, que pressupõe a responsabilidade objetiva do ente estatal pelos danos causados por seus agentes.

Desta forma, em mais uma adaptação do direito à sociedade, surge a teoria do risco administrativo, que Segundo Cavalieri Filho (2010), possui a filosofia de atribuir ao Estado a responsabilidade pelo risco criado pela sua atividade administrativa. Surgindo então como expressão concreta do princípio da igualdade dos indivíduos diante dos encargos públicos, repartindo assim todos os ônus e encargos sociais, por todos que se beneficiam da administração pública, sendo eu toda a lesão sofrida pelo particular deve ser ressarcida, independente de culpa do agente público que o causou. O que se deve verificar é apenas a relação de causalidade entre ação administrativa e o dano sofrido pelo administrado.

Assim, como o estado está sobre o controle de uma atividade de risco, este deve reparar os danos decorrentes daquela, haja visto que a atividade de controle da administração pública é praticada em favor de todos, da mesma forma deve se responder pelos atos que resultaram em dano, independente da comprovação de culpa, visto que o estado como o ente soberano possui muito mais capacidade de produção de provas, esta é a teoria utilizada nos dias atuais.

Existe ainda a figura da teoria do risco integral, contudo esta teoria está longe de ser aceitável, pois coloca a administração pública culpada de todos os danos que venham a acontecer, desprezando as possibilidades de isenção da responsabilidade civil do estado, tópico que ainda será abordado.

Nesta teoria não existe a possibilidade do estado se desincumbir da reparação como elenca o grande Doutrinador brasileiro de direito administrativo, Hely Lopes Meirelles: 
a teoria do risco integral é a modalidade extremada da doutrina do risco administrativo, abandonada, na prática, por conduzir ao abuso e à iniquidade social. Por essa fórmula radical a Administração Pública ficaria obrigada a indenizar todo e qualquer dano suportado por terceiros, ainda que resultante de culpa ou dolo da vítima. (MEIRELLES, 1999, p. 586)

Sendo assim, não há a possibilidade de seu uso na prática, sendo utilizado apenas para trazer discussão acerca da temática abordada, aumentando o escopo de pesquisa.

\subsection{CONCEITOS DAS TEORIAS}

\subsubsection{RESPONSABILIDADE CIVIL OBJETIVA DO ESTADO}

Elencada na carta magna, em seu artigo $37, \S 6^{\circ}$, é aquela em que não se tem como obrigação o elemento culpa, ou seja, demonstrado o ato, o dano e o nexo de causalidade entre eles deve-se promover a devida indenização, esta é a teoria utilizada no ordenamento jurídico brasileiro, fruto de diversas discussões e estudos, para ilustrar e realizar uma abordagem realística vejamos a seguinte jurisprudência do Tribunal de Justiça do Estado de São Paulo:

RESPONSABILIDADE CIVIL DO ESTADO - Autor que foi submetido a procedimento de lavagem intestinal para a realização de ultrassonografia dos rins -Procedimento que resultou na laceração da mucosa do reto, causando dano à sua saúde- Existência de nexo causai, resultando na responsabilidade civil do Estado - Fixação de indenização por danos morais - Reforma da sentença de improcedência - Recurso provido.

(TJ-SP - APL: 990103648200 SP, Relator: Magalhães Coelho, Data de Julgamento: 26/10/2010, 3a Câmara de Direito Público, Data de Publicação: 10/11/2010) 
No caso acima, o autor intentou ação de reparação por danos morais e materiais contra o estado, pois, realizou um procedimento que resultou em uma laceração da mucosa do reto, causando danos a sua saúde, o juízo de piso entendeu que não houve a devida comprovação de culpa do estado na presente demanda, e negou os pedidos do autor, que interpôs recurso de apelação, no qual o Tribunal conheceu e deu provimento ao pedido de dano moral, fixando em $R \$ 100.000,00$ (cem mil reais), por entender que na presente demanda não resta-se necessário a comprovação de culpa do estado, haja visto que não houve erro médico, portanto necessário se faz apenas em comprovar o dano, ato ilícito e nexo de causalidade, que foram devidamente comprovados, vejamos parte do voto do relator:

Com efeito, a saúde é um serviço público que deve ser prestado satisfatoriamente pelo Estado (art. 196 da CF), de forma que, se este deixar de agir ou agir deficientemente responderá pelos danos causados, independentemente da existência de culpa. Consoante cediço, a responsabilidade objetiva do Estado em indenizar, decorrente do nexo causai entre $o$ ato administrativo e o dano causado ao particular, prescinde da apreciação dos elementos subjetivos, de forma que os referidos vícios na manifestação da vontade dizem respeito, apenas, ao eventual direito de regresso (art. 37, § 6 , da CF). (TJ-SP - APL: 990103648200 SP, Relator: Magalhães Coelho, Data de Julgamento: 26/10/2010, 3a Câmara de Direito Público, Data de Publicação: $10 / 11 / 2010)$

Desta maneira, ratifica-se o que adota a doutrina, o que levou tanto tempo para se firmar, nos casos em que existe o ato do estado, não se faz necessário a comprovação de culpa, o que é determinante dentro de uma estratégia processual, como visto no caso concreto, por sua felicidade teve o autor sua sentença reformada e prestada efetiva Justiça.

Um caso clássico de responsabilidade objetiva, é o famoso caso de Agnés Blanco, que ocorreu no ano de 1871, onde foi ferida ao passar em frente a uma fábrica estatal, comandada por quatro funcionários, em decorrência deste ferimento teve sua perna 
amputada, assim seu pai ingressou com uma ação judicial em face do Estado, visando a indenização a fim de reparar o dano causado à sua filha, por decisão do tribunal, foi concedida à vítima uma pensão vitalícia, surgindo assim a teoria do risco administrativo, que pressupõe a responsabilidade objetiva do ente estatal pelos danos causados por seus agentes.

\subsubsection{RESPONSABILIDADE CIVIL DO ESTADO POR OMISSÃO}

A lei 8.080 de 19 de setembro de 1990, regula o serviço da saúde para a população estabelecendo regras e princípios que devem ser seguidos para uma correta e ilibada prestação pública desse direito promulgado na constituição federal brasileira, incluindo ainda as instituições privadas.

Assim em seu artigo $2^{\circ}$ a lei nos diz:

Art. $2^{\circ}$ A saúde é um direito fundamental do ser humano, devendo o Estado prover as condições indispensáveis ao seu pleno exercício.

$\S 1^{\circ} \mathrm{O}$ dever do Estado de garantir a saúde consiste na formulação e execução de políticas econômicas e sociais que visem à redução de riscos de doenças e de outros agravos e no estabelecimento de condições que assegurem acesso universal e igualitário às ações e aos serviços para a sua promoção, proteção e recuperação.

$\S 2^{\circ}$ O dever do Estado não exclui o das pessoas, da família, das empresas e da sociedade.

Art. 3ํㅡㄹ Os níveis de saúde expressam a organização social e econômica do País, tendo a saúde como determinantes e condicionantes, entre outros, a alimentação, a moradia, o saneamento básico, o meio ambiente, o trabalho, a renda, a educação, a atividade física, o transporte, o lazer e o acesso aos bens e serviços essenciais. (Redação dada pela Lei ํㅜ 12.864, de 2013) 
Parágrafo único. Dizem respeito também à saúde as ações que, por força do disposto no artigo anterior, se destinam a garantir às pessoas e à coletividade condições de bem-estar físico, mental e social.

Logo resta-se claro que o direito a saúde é de toda a população, sendo assim nos casos em que o Estado deixar de prestar o devido serviço, ou seja, deixar de fazer valer a lei supracitada, este deve suportar o peso da responsabilização, restando claro que este não conseguiu atingir os objetivos impostos a ele, falhou, portando deve suportar este ônus.

Ainda constitui como princípio, insculpido em seu artigo $7^{\circ}$, II, que o estado deve proporcionar a integralidade de assistência, sendo assim, deve proporcionar à sociedade, todo o cuidado com a saúde, seja ele físico, mental, preventivo, contencioso, urgente. Desta maneira, caso haja uma falha, e esta seja comprovada, o estado deverá arcar com seus prejuízos.

Com isso, passa-se a análise do ordenamento jurídico brasileiro, no sentido da responsabilidade civil por omissão, que não existe de forma expressa em nosso sistema de leis, contudo jurisprudência e doutrina, não se desincumbiram dessa obrigação, trazendo variadas discussões acerca da temática, obteve-se uma corrente, mas o entendimento não é uníssono variando acerca de cada caso.

A teoria majoritária se expressa na existência do elemento culpa, pois existe o pensamento de que se o Estado se omitiu, deve-se haver a constatação se este deveria realmente agir, assim nos diz Lucia Vale Figueiredo:

ainda que consagre o texto constitucional a responsabilidade objetiva, não há como se verificar a adequabilidade da imputação ao Estado na hipótese de omissão, a não ser pela teoria subjetiva. Se o Estado se omitiu, há de se perquirir se havia o dever de agir. Ou, então, se a ação estatal teria sido defeituosa a ponto de se caracterizar insuficiência da prestação do serviço. (MALHEIROS, 1994, p. 172). 
Contudo, como supracitado este pensamento não é sedimentado existe-se bastante discussão sobre a temática, alguns doutrinadores seguem a linha da responsabilidade civil objetiva em todos os casos e outros inclusive a jurisprudência segue a linha de que deve haver nos casos de omissão a constatação de culpa.

Em oportunidade posterior, em capítulo próprio será demonstrado o entendimento jurisprudencial, acerca da temática abordada, para assim demonstrar de forma mais ampla o entendimento e aplicação dos temas acima expostos.

Vale dizer, que apesar da jurisprudência seguir a corrente da responsabilidade civil subjetiva, nada impede de haver mudanças e esta perspectiva destoar, afinal estamos falando sobre uma ciência em constante evolução, ademais deve-se sempre analisar caso por caso, em determinadas ocasiões se faz necessário interpretar a demanda por vários ângulos afim de que seja dada a devida prestação jurisdicional.

Em nossa Constituição Federal especificamente em seu art. 37, § 6º, estipula-se que neste tipo de responsabilidade, aquela que se auferi culpa ou dolo, a entidade intentará ação de regresso, para reaver a quantia dissipada, dessa forma observa-se que faz-se necessário demonstrar a culpa do agente quando o estado estiver sendo responsabilizado por uma omissão.

Deste modo, nos casos em que se envolve a saúde pública, caso o ato seja omissivo, deve-se haver a demonstração de culpa, apesar de haver na Constituição Federal preceito expresso no sentido de que toda responsabilidade civil do estado objetiva, deve - se analisar o caso concreto.

Como dito alhures a ciência jurídica não é engessada igual a fórmulas prontas de cálculos, muito pelo contrário, ela se molda em cada caso concreto. O que ocorre aqui não é diferente, não é correto dizer que em todos os casos em que um ato omissivo do estado que gerou dano, será apenas reparado constatando a figura da culpa, existe no pensamento doutrinário moderno a diferença entre culpa específica e culpa genérica, enquanto aquela não se faz necessário a demonstração do elemento culpa, nesta se faz. 
Enquanto a culpa específica, esta é caracterizada pela responsabilidade direta, pois o estado tem a possibilidade de agir no caso concreto e não o faz, a culpa genérica é aquela em que se deve comprovar que o estado deveria agir, titulando-se assim a responsabilidade civil subjetiva, vejamos o que leciona Guilherme Couto de Castro:

não ser correto dizer, sempre, que toda hipótese de dano proveniente de omissão estatal será encarada, inevitavelmente, pelo ângulo subjetivo. Assim o será quando se tratar de omissão genérica. Não quando houver omissão específica, pois aí há dever individualizado de agir. (CASTRO, 2007, p. 231).

Assim está posicionada a doutrina moderna, deve-se individualizar a demanda, auferindo desta forma qual tipo de omissão restou-se configurada, os tribunais possuem o mesmo entendimento, afinal, deve-se sempre individualizar qualquer demanda e assim enxergar a melhor saída a ela.

Desta forma, afirma-se que mesmo nos casos em que houve um ato omissivo por parte do estado (por meio de seus agentes públicos) para que se tenha a reparação deve-se analisar, caso o Estado esteja na posição de garante, hipótese em que pessoas ou coisas estão sobre sua demanda, impera a teoria objetiva, pautada na modalidade de Risco Administrativo.

\subsection{CAUSAS EXCLUDENTES DE RESPONSABILIDADE ESTATAL}

Seria contraditório e irracional, que uma pessoa seja responsabilizada pelo que não cometeu, sendo por culpa exclusiva de vítima, culpa de terceiros, ou qualquer outra possibilidade que retire o nexo de causalidade, sendo assim surgem-se as causas de excludente de responsabilidade civil.

Como dito, retira-se o nexo de causalidade, elemento que caso não seja identificado, faz se sucumbir a possibilidade de reparação de dano, ora, se não há um nexo entre o ato e o dano, não há que se falar em qualquer tipo de indenização, temos então a culpa exclusiva da vítima, ato de terceiro, caso fortuito e na força maior. 
Neste diapasão recente julgado acerca da temática:

APELAÇÃO CÍVEL. CONCURSO PÚBLICO. AÇÃO ORDINÁRIA. CARGO DE TÉCNICO DE ENFERMAGEM. DANOS MORAIS E MATERIAIS NÃO CONFIGURADOS. FALTA DE DOCUMENTO EXIGIDO NO EDITAL. AUSÊNCIA DE ILEGALIDADE NO ATO PRATICADO. SENTENÇA MANTIDA. 1.0 art. 37, § 6º, da Constituição da República consagra a opção constitucional pela Teoria do Risco Administrativo, segundo a qual, em apertada síntese, as pessoas jurídicas de direito público e as de direito privado prestadoras de serviços públicos responderão objetivamente pelos danos que causarem, bastando que sejam comprovados a conduta do ente, o dano e o nexo de causa entre um e outro. Como requisitos negativos da responsabilização, o fato danoso não pode ter decorrido de fato exclusivo da vítima ou de terceiros, caso fortuito ou força maior (excludentes da responsabilidade civil do Estado). 2. Caso concreto em que restou caracterizada a culpa exclusiva da parte autora, que não possuía, em tempo hábil, a habilitação legal (inscrição no COREN na categoria de técnico de enfermagem) para firmar a assinatura do Termo de Aceitação e Admissão por Tempo determinado. Sentença mantida. RECURSO DESPROVIDO. (Apelação Cível № 70068485325, Terceira Câmara Cível, Tribunal de Justiça do RS, Relator: Marlene Marlei de Souza, Julgado em 22/11/2018).

(TJ-RS - AC: 70068485325 RS, Relator: Marlene Marlei de Souza, Data de Julgamento: 22/11/2018, Terceira Câmara Cível, Data de Publicação: Diário da Justiça do dia 27/11/2018)

\subsubsection{CULPA EXCLUSIVA DA VÍTIMA E ATO DE TERCEIRO}

Aqui a compreensão é de fácil assimilação, existe o dano, a culpa deste dano é exclusiva da vítima ou concorrente, caso o estado consiga comprovar a reparação torna - se, inviável haja visto que o dano independeu dos atos de seus agentes, sendo 
eles omissivos ou comissivos, na possibilidade de culpa concorrente os ônus podem ser diminuídos.

Assim segue a corrente do Supremo Tribunal Federal na figura do Relator Francisco Rezek, que foi muito feliz em sua colocação:

Embora tenha a Constituição admitido a responsabilidade objetiva, aceitando mesmo a teoria do risco administrativo, fê-lo com temperamentos, para prevenir os excessos e a própria injustiça. Não obrigou, é certo, à vítima e aos seus beneficiários, em caso de morte, a prova da culpa ou do dolo do funcionário para alcançar a indenização. Não privou, todavia, o Estado a propósito de eximir-se da reparação, alegando que o dano defluíra do comportamento doloso ou culposo da vítima. (STF, 2a. Turma, julgado em 5.12.89. Rel. Francisco Rezek, RTJ 131/417 e RDA 179/180")

Desta maneira, como sedimentado, há a possibilidade de isenção de responsabilidade do Estado frente a culpa exclusiva da vítima ou de terceiros, devendo-se ser observado em cada caso se houve a figura de um destes.

\section{APLICABILIDADE DO ENTENDIMENTO JURISPRUDENCIAL}

A faceta prática e realística deve ser levada em consideração, haja visto que o assunto produz diversas demandas, que em vários tribunais é discutida, produzindo assim diverso acervo decisório acerca da temática, resta-se então necessário trazer a baila tão importantes julgados.

Vejamos um recente julgado do TJ/DF datado de 15/05/19, que traz uma ilustração ao que foi dito sobre a responsabilidade civil por omissão de seus agentes:

APELAÇÃO. ADMINISTRATIVO, CIVIL E PROCESSUAL CIVIL. AÇÃO INDENIZATÓRIA. RESPONSABILIDADE CIVIL DO ESTADO. ACIDENTE AUTOMOBILÍSTICO. HOSPITAL DA REDE PÚBLICA DE SAÚDE. FRATURA NO JOELHO. LESÃO PERMANENTE. PROVA 
PERICIAL. CONSTATAÇÃO DO DANO E DO NEXO DE CAUSALIDADE. OMISSÃO. FALHA NA PRESTAÇÃO DO SERVIÇO DE SAÚDE. OBRIGAÇÃO DE INDENIZAR. DANOS MORAIS CONFIGURADOS. QUANTUM. DANOS MATERIAIS NÃO COMPROVADOS. RECURSO CONHECIDO E PARCIALMENTE PROVIDO. 1. A responsabilidade civil do Estado, seja ela por ato comissivo ou omissivo, não dispensa a necessária prova de seus pressupostos, incluindo o fato administrativo, o dano sofrido e o nexo causal entre o evento danoso e a ação ou omissão de agente público. Ressalta-se que a hipótese dos autos é de responsabilidade civil por omissão genérica, ante o descumprimento de ordens de caráter geral. Desse modo, em atenção à teoria do faute du service, a configuração da responsabilidade do Estado depende da caracterização de sua inércia, omissão ou falha na prestação do serviço, ou seja, deverá ser demonstrada a culpa estatal. 2. Da análise do arcabouço fáticoprobatório, verifica-se que, durante a internação do autor, ora apelante, no Hospital de Base, foram observadas e registradas no prontuário médico inflamações, edemas e dificuldade de movimentação de seu membro inferior esquerdo e, inclusive, houve solicitação de avaliação ortopédica, sem informações nos autos de que foi realizada. Ainda, $\underline{0}$ paciente teve alta médica sem receber o tratamento médico em seu joelho esquerdo. 3. Evidenciada, após realização de prova pericial, a falha na prestação do serviço de saúde de hospital da rede pública e a constatação de que as lesões irreparáveis existentes no joelho do autor poderiam não existir ou ser minimizadas se a fratura tivesse sido tratada em momento oportuno (janela da oportunidade cirúrgica), há configuração do nexo de causalidade e, por conseguinte, do dever de indenizar. 4. Observa-se, a par de tal quadro, a existência de dano moral sofrido pelo autor, devendo a v. sentença ser reformada quanto ao ponto. Com efeito, as consequências decorrentes da ausência de tratamento adequado e da consolidação viciosa dos ossos do joelho do recorrente, sobretudo diante da deformidade de joelho e pé esquerdos, com 
comprometimento da mobilidade dos membros e possibilidade de alterações funcionais e dores, constituem grave violação a atributo da personalidade afeto à integridade física, psíquica e à dignidade do autor, a configurar dano moral indenizável. O quadro exposto, fugindo à normalidade, ultrapassa o mero dissabor, por ter causado aflições e angústias ao recorrente. 5. Diante da gravidade do dano e das peculiaridades do caso concreto, revela moderação e se amolda ao conceito de justa reparação a quantia de $R \$ 15.000,00$ (quinze mil reais), a título de compensação pelos danos morais sofridos pelo apelante, atendendo, assim, ao caráter compensatório e dissuasório da indenização, sem constituir, de outro norte, enriquecimento sem causa da vítima. 6. Não merece prosperar a pretensão do apelante de ser indenizado a título de danos materiais, haja vista a ausência de comprovação da efetiva perda patrimonial do autor, o que obsta a condenação do ente distrital ao pagamento da pretendida indenização 7. Recurso conhecido e parcialmente provido.

(TJ-DF 07000068120168070018 DF 0700006-81.2016.8.07.0018, Relator: SANDRA REVES, Data de Julgamento: 15/05/2019, 2ª Turma Cível, Data de Publicação: Publicado no DJE: 21/05/2019 . Pág.: Sem Página Cadastrada.)

Como dito alhures, existe a diferença entre culpa genérica e culpa específica, sendo que aquela depende de comprovação, no caso acima percebe-se, que a culpa observada, é a genérica, sendo assim se fez necessário a sua comprovação, o que restou devidamente provado, fez jus ao requerente a devida indenização, restando-se efetivado o entendimento atribuído ao presente trabalho.

Noutro giro, vejamos recente julgado do Tribunal do Piauí, apontando a culpa específica na qual, mesmo sendo um caso de omissão do Estado, segue-se a teoria do risco administrativo, ou seja, sem a necessidade de comprovação do elemento culpa, responsabilidade objetiva configurada: 
ADMINISTRATIVO E PROCESSUAL CIVIL. RESPONSABILIDADE CIVIL DO ESTADO. CONDUTA OMISSIVA. RESPONSABILIDADE OBJETIVA. TEORIA DO RISCO ADMINISTRATIVO. TESE FIXADA EM REPERCUSSÃO GERAL. OMISSÃO ESPECÍFICA. NÃO PRESTAÇÃO DE SERVIÇO PÚBLICO DE SAÚDE. CONFLITO ENTRE SERVIDOR E PACIENTE. VIOLAÇÃO DOS DIREITOS À VIDA, À SAÚDE E À INTEGRIDADE FÍSICA. DANO MORAL IN RE IPSA. DANO MATERIAL. NEXO CAUSAL CONFIGURADO. SENTENÇA MANTIDA. HONORÁRIOS ADVOCATÍCIOS RECURSAIS. DESNECESSIDADE. ENUNCIADO ADMINISTRATIVO № 07 DO STJ. RECURSO CONHECIDO E IMPROVIDO. 1. Em ações de responsabilidade civil do Estado, não deve ser deferida a denunciação da lide do servidor público responsável pelo ato, se restar evidenciado o prejuízo à celeridade processual. Precedentes do STJ. 2. Conforme tese fixada em repercussão geral, pelo STF, a responsabilidade civil estatal, segundo a Constituição Federal de 1988, em seu artigo 37 , § 6을 subsume-se à teoria do risco administrativo, tanto para as condutas estatais comissivas quanto paras as omissivasÂÂ" (STF, RE 841526, Relator (a): Min. LUIZ FUX, Tribunal Pleno, julgado em 30/03/2016). 3. A conduta de deixar de prestar atendimento a determinado indivíduo, em hospital público, após conflito entre o servidor público responsável e o paciente, caracteriza a omissão específica do Estado, que atrai a sua responsabilidade civil. 4. Configurada a conduta estatal danosa, que viola o direito fundamental à vida, à saúde e à integridade física, resta configurado também o dano moral, que, na hipótese, é in re ipsa. 5. Também restou comprovado o dano material, consistente no valor de consulta particular de urgência, tendo em vista que o autor somente buscou a rede privada de saúde após Ihe ter sido omitida especificamente a prestação do serviço público, havendo, in casu, liame causal entre conduta e dano. 6. Em recursos interpostos anteriormente à entrada em vigor do $\mathrm{CPC} / 2015$, não é possível a fixação de novos honorários advocatícios. Enunciado Administrativo oㅡ 07 do STJ. 7. Apelação conhecida e improvida. 
(TJ-PI - AC: 00023410820128180032 PI, Relator: Des. Francisco Antônio Paes Landim Filho, Data de Julgamento: 11/10/2018, 3ª Câmara de Direito Público)

No caso acima houve a constatação da culpa específica, haja visto que servidor público negou atendimento a paciente após conflito com o paciente, demonstrando assim que o Estado se omitiu diante de um momento específico, deixando de atender o paciente, causando danos que devem e foram reparados, inclusive os danos materiais com a consulta em médico particular.

Desta maneira, observa-se que existem discussões elementares acerca da temática, devendo-se lembrar que cada caso comporta um ângulo de interpretação, especificamente nos casos em que há omissão por parte do Estado no que concerne a área da saúde pública, deve-se auferir qual o tipo de culpa e assim classificar qual o tipo de responsabilidade civil deve ser aplicada, repise-se ainda que o direito é uma ciência em constante evolução que se move por doutrina, jurisprudência, julgados, leis, grupos sociais, e demais grupos.

Portanto, resta-se cristalino o entendimento da importância desse processo indenizatório, haja visto um administrado em situação de hipossuficiência perante o Estado, observadas as nuances de cada caso se faz presente uma devida prestação jurisdicional sempre com proporção ao dano causado.

\section{AÇÃO DE REGRESSO NAS CONDUTAS OMISSIVAS}

A ação de regresso pode ser utilizada, tendo respaldo jurídico, assim como assevera o artigo 0 art. 37, $\S 6^{\circ}$, Carta Magna:

$\S 6$ - As pessoas jurídicas de direito público e as de direito privado prestadoras de serviços públicos responderão pelos danos que seus agentes, nessa qualidade, causarem a terceiros, assegurado o direito de regresso contra o responsável nos casos de dolo ou culpa. 
A ação de regresso é a correta, para que não se tenha nos casos de dolo ou culpa do agente público, prejuízo ao erário, assim como o bem público não possui dono, pertencendo a todos da sociedade, todos os prejuízos que possam ser reduzidos, devem ser observados, desta forma, observado o que concerne a legislação, existe a possibilidade da ação de regresso e esta deve ser utilizada, vejamos um caso concreto, julgado pelo Tribunal de Justiça de Minas Gerais:

ADMINISTRATIVO - AÇÃO DE REGRESSO - SERVIDOR PÚBLICO ESTADUAL - COMETIMENTO DE INFRAÇÃO DE TRÂNSITO - MULTA PAGA COM RECURSOS PÚBLICOS - ORDEM DE RESTITUIÇÃO DA QUANTIA - JUROS DE MORA - TERMO INICIAL - EVENTO DANOSO - RECURSO PROVIDO. Em se tratando de responsabilidade do servidor, pela via ressarcitória, por dano material arcado pelo Estado, incidem juros de mora desde a data do evento danoso. Inteligência da Súmula ํo. 54 do col. Superior Tribunal de Justiça.

(TJ-MG - AC: 10024101984409001 MG, Relator: Sandra Fonseca, Data de Julgamento: 03/12/2013, Câmaras Cíveis / 6ª CÂMARA CíVEL, Data de Publicação: 17/12/2013)

No presente caso, um servidor público teve que devolver ao Estado de Minas Gerais os valores gastos em uma reparação de acidente de trânsito causado por ele, provouse a culpa do servidor que não observou a placa "PARE", causando a colisão com veículo de um particular, o Estado reparou o dano e intentou ação de regresso, que foi julgada procedente.

Com intuito de complementação, não sendo objeto de estudo nesse artigo, além dos agentes responderem civilmente, no que diz respeito aos atos ilícitos praticados, ainda há a punição na esfera administrativa em que, após processo administrativo disciplinar poderá punir com demissão seu servidor, bem como na seara penal, mais precisamente do artigo 319 ao 320 do Código Penal Brasileiro, tais aplicabilidades ainda encontram escopo nos artigos 121 ao 124 da Lei Federal no 8.112/90. 
Portanto, como visto, não há muita discussão acerca da temática, doutrina e jurisprudência possuem a mesma corrente de pensamento, sendo assim, caso seja comprovada a culpa do agente público, o Estado procederá com a reparação, e demandará contra este a ação de regresso, afim de que não seja efetivado prejuízo que não dependeu do ente público.

\section{CONSIDERAÇÕES FINAIS}

As condutas dos agentes da administração pública são monitoradas, mesmo quando estes não atuam são de certa forma punidos. Essas omissões muitas vezes resultam em consequências muitas vezes irreversíveis, como na área da saúde, onde é dever de todos os agentes promove-la de forma que toda a sociedade possa ter esse direito garantido, assim como elencado na Constituição Federal da República.

A partir das pesquisas realizadas, pôde-se entender que são muitas as teorias existentes a partir dessa temática, a teoria doutrinária entende que a responsabilidade a ser adotada deve ser, a outra que é a jurisprudencial entende que a responsabilidade do agente pelas condutas omissivas deve ser subjetiva, e a terceira que entende que deve ser analisado primeiramente o caso concreto para depois aplicar a responsabilidade objetiva ou então a subjetiva.

As decisões dos tribunais superiores de justiça foram imperiosas em decidir que a responsabilidade deve ser considerada subjetiva, analisando assim, se a conduta omissiva do agente, juntamente com a negligência administrativa, foram causadoras da lesão, para, a partir disso, a administração ser responsabilizada pelas lesões causadas. Em muitas, praticamente na maioria das vezes, condutas omissivas na área da saúde resultam em lesões de difícil reparo ou até mesmo irreversíveis, por isso se verificado o nexo entre a lesão e a conduta, deve haver a indenização à vítima lesionada.

Durante a pesquisa, também foi possível verificar que há situações em que ocorrem condutas específicas do Estado, que sempre que houver a omissão de determinada 
conduta, a lesão sempre será considerada responsabilidade da administração, assim sendo considerada a responsabilidade objetiva.

Em suma, atualmente o entendimento predominante em decisões judiciais é considerar a responsabilidade como subjetiva, analisando-se assim, caso por caso, e assim determinar a necessidade de reparação da lesão, ou considerar a lesão como não sendo decorrente da conduta omissiva do Estado, que baseando em dados colhidos, essa segunda situação pouco ocorre.

Ao longo da pesquisa, ficou nítida a necessidade de unificar as decisões dos tribunais, a fim de que seja estabelecido somente um entendimento acerca da responsabilidade estatal sobre as condutas de seus agentes, sejam essas de forma omissiva ou comissiva.

A responsabilidade objetiva é a que mais se adéqua a maioria dos casos, já que a administração está envolta pela teoria do risco administrativo, o que demonstra a coerência do pressuposto da responsabilidade objetiva, seja nos casos em que há omissão por parte dos agentes/Estado, seja também pelas condutas comissivas, praticadas na área da saúde.

Somente assim, será respeitado o direito fundamental à saúde, que deve ser prestado da melhor maneira a toda a sociedade, já que elencado como fundamental na Constituição da República Federativa do Brasil de 1988, fazendo jus também ao disposto no art. $37, \S 6^{\circ}$ do referido dispositivo, que prevê a responsabilização pelos danos causados durante a prestação de serviços públicos, danos esses causados pelos agentes, configurando a omissão à prestação da saúde como dano, já que como direito fundamental, a ausência de sua disponibilidade resulta em danos a terceiros, muitas vezes irreparáveis. Portanto, necessária a adoção da responsabilidade objetiva como parâmetro na aplicação de sanções, não sendo necessário para tanto, a culpa do agente. 


\section{REFERENCIAS}

BRASIL. Constituição da República Federativa do Brasil. Vade mecum. 12. Ed. São Paulo: Saraiva, 2011.

. Decreto Lei no 2.848, de 07 de Dezembro de 1940. Código Penal. Diário Oficial da União. Rio de Janeiro.

. Lei № 8.112, De 11 De Dezembro De 1990. Diário Oficial da União. Brasília.

CASTRO, Guilherme Couto de. Programa de Responsabilidade Civil, $7^{a}$ ed., Atlas, 2007, p. 231

DI PIETRO, Maria Sylvia Zanella. Direito Administrativo. 12 edição. São Paulo: Editora Saraiva, 2018.

FIGUEIREDO, Alexandre. 0 caso Blanco. Disponível em: http://alexandreadministrativo.blogspot.com/2011/05/o-caso-blanco.html. Acesso em: 20-10-2019.

GANDINI, João Augusto Donizeti; SALOMÃO, Diana Paola da Silva. $\boldsymbol{A}$ reponsabilidade civil do Estado por conduta omissiva. Disponível em: https://jus.com.br/artigos/4365/a-responsabilidade-civil-do-estado-por-condutaomissiva/2. Acesso em: 06-04-2019.

LIRIO, Dulce Back Rocha. Da reponsabilidade do Estado por omissão no serviço à saúde. Disponível em: https://advocacialirio.jusbrasil.com.br/artigos/396248794/daresponsabilidade-do-estado-por-omissao-no-servico-a-saude. Acesso em: 05-042019.

MARINELA, Fernanda. Direito Administrativo. $31^{\text {a }}$ edição. São Paulo: Editora Atlas, 2018.

MEIRELLES, Hely Lopes. Direito Administrativo Brasileiro. 24를. ed., São Paulo, Malheiros, 1999 (p. 586). 
MELLO, Celso Antônio Bandeira. Curso de direito administrativo. $32^{a}$ ed. São Paulo. Malheiros, 2015.

MELLO, Oswaldo Aranha Bandeira de apud CAVALIERI FILHO, Sérgio. Programa de responsabilidade civil. 9ª ed. São Paulo: Atlas, 2010, p. 243.

Enviado: Novembro, 2019.

Aprovado: Junho, 2020. 